\title{
Influence of High-Pressure Torsion Straining Conditions on Microstructure Evolution in Commercial Purity Aluminum
}

\author{
Yoshikazu Todaka*1, Minoru Umemoto, Ayumi Yamazaki*2, Jun Sasaki*3 and Koichi Tsuchiya*4 \\ Department of Production Systems Engineering, Toyohashi University of Technology, Toyohashi 441-8580, Japan
}

The influence of heat generation during severe plastic deformation on microstructure evolution was investigated in commercial purity aluminum (Al 1050, CP-Al) by using high-pressure torsion (HPT) process. The microstructure was characterized by the observations of the torsion and the longitudinal planes. CP-Al disks were deformed by HPT-straining up to 20 turns (equivalent strain, $\varepsilon_{e q}$, of $\sim 600$ ) at 0.2 or $5 \mathrm{rpm}$ at room temperature. To prevent the increase in specimen temperature, HPT-straining was also carried out in liquid nitrogen. In the all conditions, the value of Vicker's microhardness, $H v$, was saturated around $0.65 \mathrm{GPa}$ and the microstructure consisted of the equiaxed grains of about $500 \mathrm{~nm}$ with quite low dislocation density. The microstructure in the early stage of HPT-straining showed the deformed (sub)structure, and then the equiaxed grain structure with high-angle boundaries formed by grain subdivision, recovery, continuous recrystallization and grain growth with increase in strain amounts and specimen temperature. [doi:10.2320/matertrans.ME200713]

(Received August 7, 2007; Accepted October 4, 2007; Published November 14, 2007)

Keywords: microstructure, grain refinement, aluminum, heat generation, high-pressure torsion (HPT), severe plastic deformation (SPD)

\section{Introduction}

Severe plastic deformation (SPD) techniques, such as high-pressure torsion (HPT), ${ }^{1)}$ equal-channel angular pressing $(\mathrm{ECAP})^{1,2)}$ and accumulative roll bonding (ARB), ${ }^{3)}$ has been an accepted procedure for producing significant grain refinement in bulk crystalline metals. Among the SPD techniques, HPT process is one of the most powerful techniques to prepare ultrafine-grained (UFG) materials owing to non-homogeneous deformation with large strain gradient. ${ }^{4-6)}$ The principle of HPT-straining bases on the procedure developed by Bridgman. ${ }^{7)}$ A thin disk is placed between two anvils and subjected to torsional straining under a high pressure. Thus, the two parameters, i.e. a number of turns applied to the disk, $N$, and a magnitude of the imposed pressure, $P$, are important in the HPT process. It is wellknown that the applied pressure reduces diffusion rate and consequently delay the recovery kinetics; higher applied pressure facilitates grain refinement and hardening. ${ }^{8-12)}$ Additionally, high pressure seems to suppress a fracture of sample. Moreover, one of the important parameters to form UFG structure is specimen temperature during deformation. The specimen temperature during HPT-straining depends on strain rate (torsional rotation speed, $R$ ) and ambient temperature.

The microstructures in the HPT-processed disks which are typically with a thickness of $1 \mathrm{~mm}$ and a diameter of $10 \mathrm{~mm}$ are usually characterized only in the torsion plane perpendicular to the torsion axis. There have been few reports in which the evolution of microstructure was investigated by characterizing in both of the torsion and the longitudinal planes. $^{12,13)}$

The present study aims to investigate the influence of HPTstraining conditions (number of turns, $N$ (amount of strain, $\varepsilon$ ),

\footnotetext{
${ }^{* 1}$ Corresponding author, E-mail: todaka@martens.pse.tut.ac.jp

${ }^{* 2}$ Graduate Student, Toyohashi University of Technology. Present address: Daido Steel Co., Ltd.

${ }^{* 3}$ Graduate Student, Toyohashi University of Technology

${ }^{*} 4$ Present address: National Institute for Materials Science, Tsukuba, Japan
}

rotation speed, $R$, and ambient temperature (specimen temperature, $T)$ ) under the constant pressure of $P=5 \mathrm{GPa}$ on microstructure evolution in a commercial purity aluminum (CP-Al). The HPT-processed disks were characterized by Vicker's microhardness, $H v$, measurement, transmission electron microscopy (TEM), scanning ion microscopy (SIM) and electron backscatter diffraction (EBSD) technique. SIM and EBSP technique were used to characterize the microstructures from the direction perpendicular to torsion axis.

\section{Experimental Procedures}

A commercial purity aluminum (Al 1050) including 0.05 $\mathrm{Si}, 0.10 \mathrm{Fe}, 0.01 \mathrm{Ti}$ in mass\% was used. The material was annealed at $600^{\circ} \mathrm{C}$ for $3.6 \mathrm{ks}$ in pure argon atmosphere, and then cut and polished into disks of diameter $10 \mathrm{~mm} \times$ thickness $0.85 \mathrm{~mm}$ for HPT-straining. The initial grain size of disk was around $102 \mu \mathrm{m}$.

Figure 1 shows the schematic illustration of a set up for HPT-straining. The disk was held between two anvils with a depression of $0.25 \mathrm{~mm}$ depth and $10 \mathrm{~mm}$ diameter opposed vertically, and was torsion-strained by rotating the lower anvil at $R=0.2 \sim 5 \mathrm{rpm}$ under $P=5 \mathrm{GPa}$. The anvil was made of high speed tool steel, DRM2, obtained from Daido

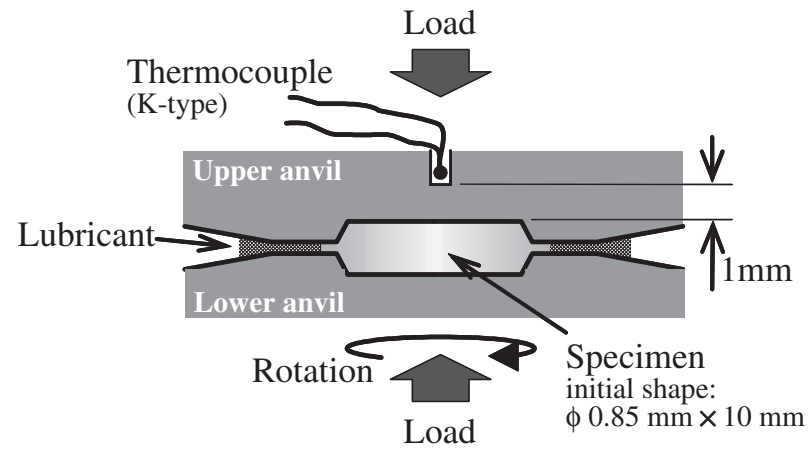

Fig. 1 Schematic illustration of a set up for HPT-straining. 


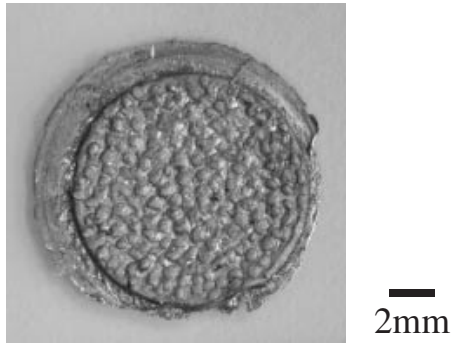

Fig. 2 Surface morphology of disk after HPT-straining; $P=5 \mathrm{GPa}, R=$ $1 \mathrm{rpm}, N=20$, R.T.

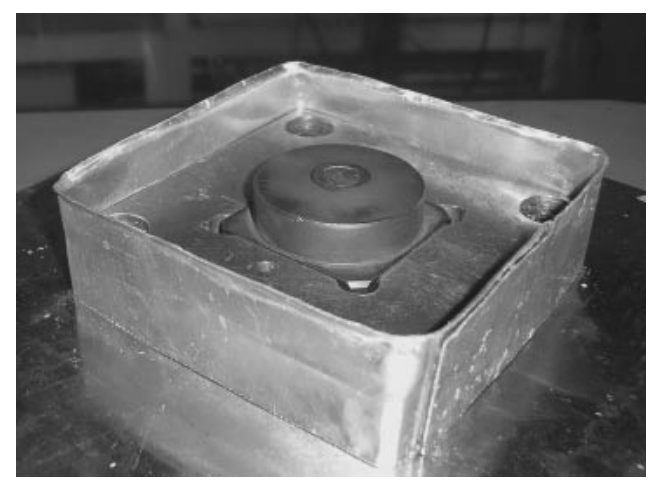

Fig. 3 Overview of a set up for HPT-straining in $\mathrm{LN}_{2}$.

Steel Co., Ltd., and was nitrided. The flat bottom of depression was roughened to increase the frictional force between the disk and the anvil. While, a lubricant containing $\mathrm{MoS}_{2}$ was applied to around the depression periphery of the lower anvil to decrease the frictional force between the anvils. As shown in Fig. 2, asperity is clearly seen at the disk surface if no slip occurred during HPT-straining. The disk flowed to the radial direction during HPT-straining due to the lack of side constraint, resulting in the reduction of thickness to about $0.6 \mathrm{~mm}$. In Fig. 2, burr is seen around the periphery of HPT-processed disk. (Part of the burr broke out when the disk was taken from the anvils.)

HPT-straining was carried out at room temperature (RT) or in liquid nitrogen $\left(\mathrm{LN}_{2}\right)$. Figure 3 shows the overview of a set up for HPT-straining in $\mathrm{LN}_{2}$. $\mathrm{LN}_{2}$ was added directly into the container to maintain complete immersion of the disk during HPT-straining. Temperature at the region of anvil around $1 \mathrm{~mm}$ away from the surface of disk center was measured by using a K-type thermocouple (Fig. 1). Hereafter, this temperature is called specimen temperature.

$H v$ measurement was carried out by using a SHIMADZU HMV-1ADW with an applied load of $4.9 \mathrm{~N}$ for $10 \mathrm{~s}$. TEM was conducted in a HITACHI H-800 operated at $200 \mathrm{kV}$. The regions about $3.2 \mathrm{~mm}$ away from the disk center were observed (Fig. 4) from the direction parallel to torsion axis. TEM samples were prepared by twin-jet electro-polishing at $253 \mathrm{~K}$ with an electrolyte solution of $30 \mathrm{vol} \% \mathrm{HNO}_{3}$ and 70 vol\% $\mathrm{CH}_{3} \mathrm{OH}$. Secondary electron (SE) micrographs were taken by SIM (SII SMI2050) at a $\mathrm{Ga}^{+}$ion current of $49.3 \mathrm{pA}$ $(30 \mathrm{kV})$. EBSD analysis was performed using an Oxford Instruments' INCA crystal EBSD system in a JEOL JSM$6500 \mathrm{~F}$ SEM with a filed emission gun operated at $12 \mathrm{kV}$.

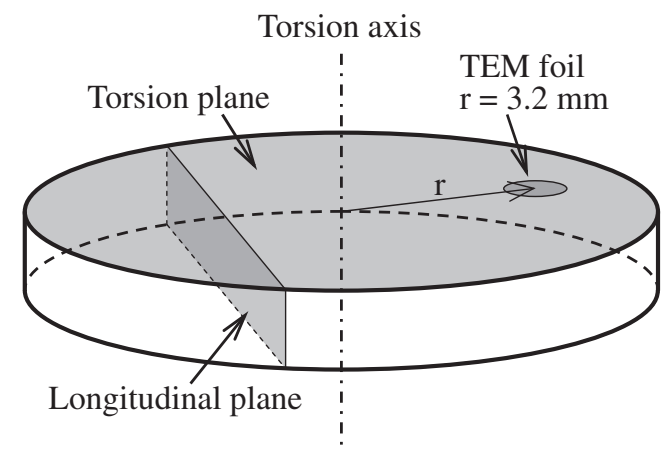

Fig. 4 Schematic illustration of observation planes in HPT disk. Equivalent strain, $\varepsilon_{e q}$, is defined by distance, $r$, from the disk center.

HKL CHANNEL5 software was used for orientation measurement and analysis. Experimental data were subjected to updating (so-called noise reduction). In the noise reduction process, non-indexed and isolated points were replaced by the most common neighboring orientation.

\section{Results}

\subsection{HPT-straining at RT}

The radial distributions of $H v$ in the disks after HPTstraining for varying turns at RT at $R=5$ or $0.2 \mathrm{rpm}$ are shown in Fig. 5. The $H v$ of non-deformed specimen was $0.22 \mathrm{GPa}$, and the $H v$ of disk compressed at $P=5 \mathrm{GPa}$ in the HPT anvils without torsion-straining was $0.39 \mathrm{GPa}$. The $H v$ distributions after HPT-straining at 5 or $0.2 \mathrm{rpm}$ showed similar changes with increase in number of turns. For smaller number of turns $(N=1 / 4)$, the $H v$ increased with distance, $r$, from the disk center, since shear strain, $\gamma$, and equivalent strain, $\varepsilon_{e q}$, are proportional to the distance according to the following equations:

$$
\begin{aligned}
& \gamma=2 \pi N r / t \\
& \varepsilon_{e q}=\gamma / \sqrt{3}
\end{aligned}
$$

where $t$ is disk thickness during torsion-straining (around $0.6 \mathrm{~mm}$ ). However, after $N=1 / 2$ at $5 \mathrm{rpm}$, the $H v$ was attained to $0.60 \mathrm{GPa}$ and the distribution of $\mathrm{Hv}$ became homogeneous in the highly strained regions $(r>1.5 \mathrm{~mm}$, $\left.\varepsilon_{e q}>4.5\right)$. The $H v$ at center regions also increased with strain gradient because the strain gradient requires the storage of geometrically necessary dislocations. ${ }^{5,6)}$ The maximum $H v$ increased slightly up to $0.65 \mathrm{GPa}$ and the distribution became homogeneous in the whole disk with increase in number of rotations. This suggests that recovery, recrystallization and/or grain growth processes occurred with high density lattice defects and heat generation in the whole disk. ${ }^{10,12,14,15)}$ After larger number of turns $(N>10)$, the $H v$ of both disks HPT-processed at 5 or $0.2 \mathrm{rpm}$ was saturated around $0.65 \mathrm{GPa}$.

Figure 6 shows the microstructure of the torsion plane after HPT-straining $\left(\varepsilon_{e q}=190\right)$ at 5 or $0.2 \mathrm{rpm}$ for $N=10$ at RT. The both bright-field (BF) images were quite similar: equiaxed grain structure with a very small number of dislocations. The careful inspections of dark-filed (DF) images show a tendency for the grains to align in the shear direction of HPT-straining. The selected-area electron dif- 

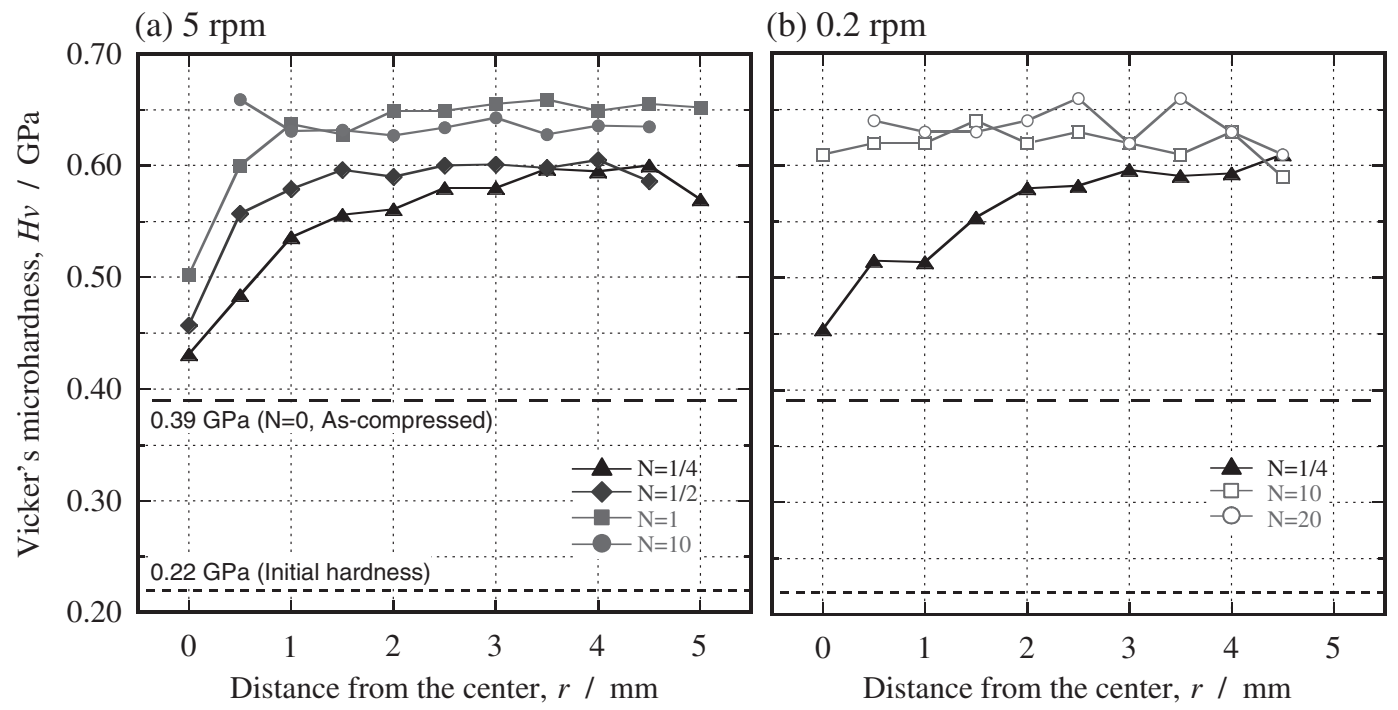

Fig. 5 Radial distributions of $H v$ in the disks processed by HPT at a rotation speed of (a) 5 rpm or (b) 0.2 rpm for varying turns at RT.
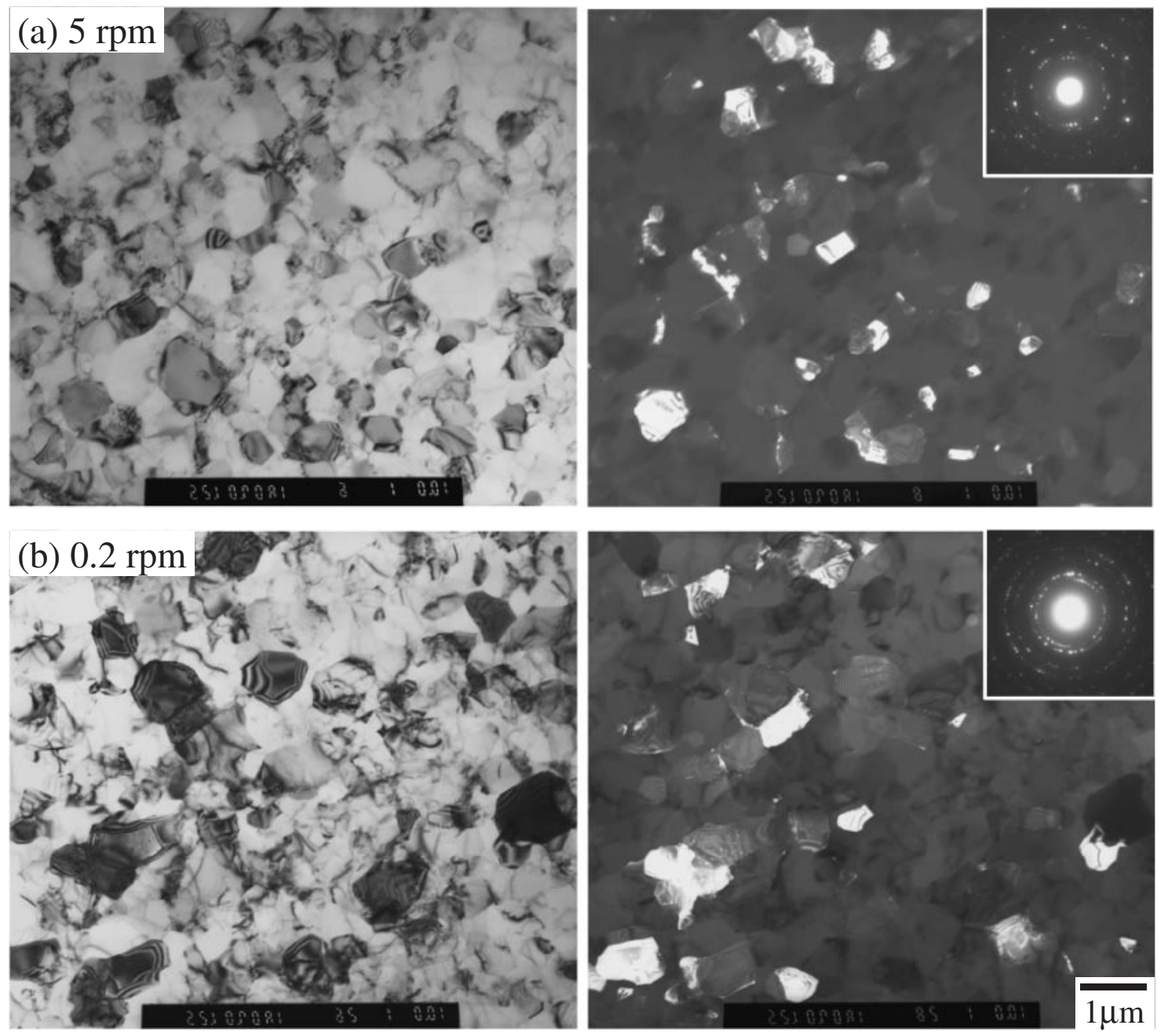

Fig. 6 Microstructure at the torsion plane region of $r=3.2 \mathrm{~mm}\left(\varepsilon_{e q}=190\right)$ after HPT-straining at a rotation speed of (a) $5 \mathrm{rpm}$ or (b) $0.2 \mathrm{rpm}$ for $N=10$ at RT. The SAED patterns were taken form the areas of $\phi 4.7 \mu \mathrm{m}$ or $\phi 9.2 \mu \mathrm{m}$ in diameter in each of the BF images.

fraction (SAED) patterns illustrate a large spread in orientations in these microstructures.

As described above, since the $H v$ distribution change and the obtained maximum $\mathrm{Hv}$ after HPT-straining at 5 and
$0.2 \mathrm{rpm}$ at RT are nearly same, the evaluation of microstructures during HPT-straining is shown about the observation results of $0.2 \mathrm{rpm}$. Figure 7 shows the EBSD maps obtained from the torsion and the longitudinal plane regions 

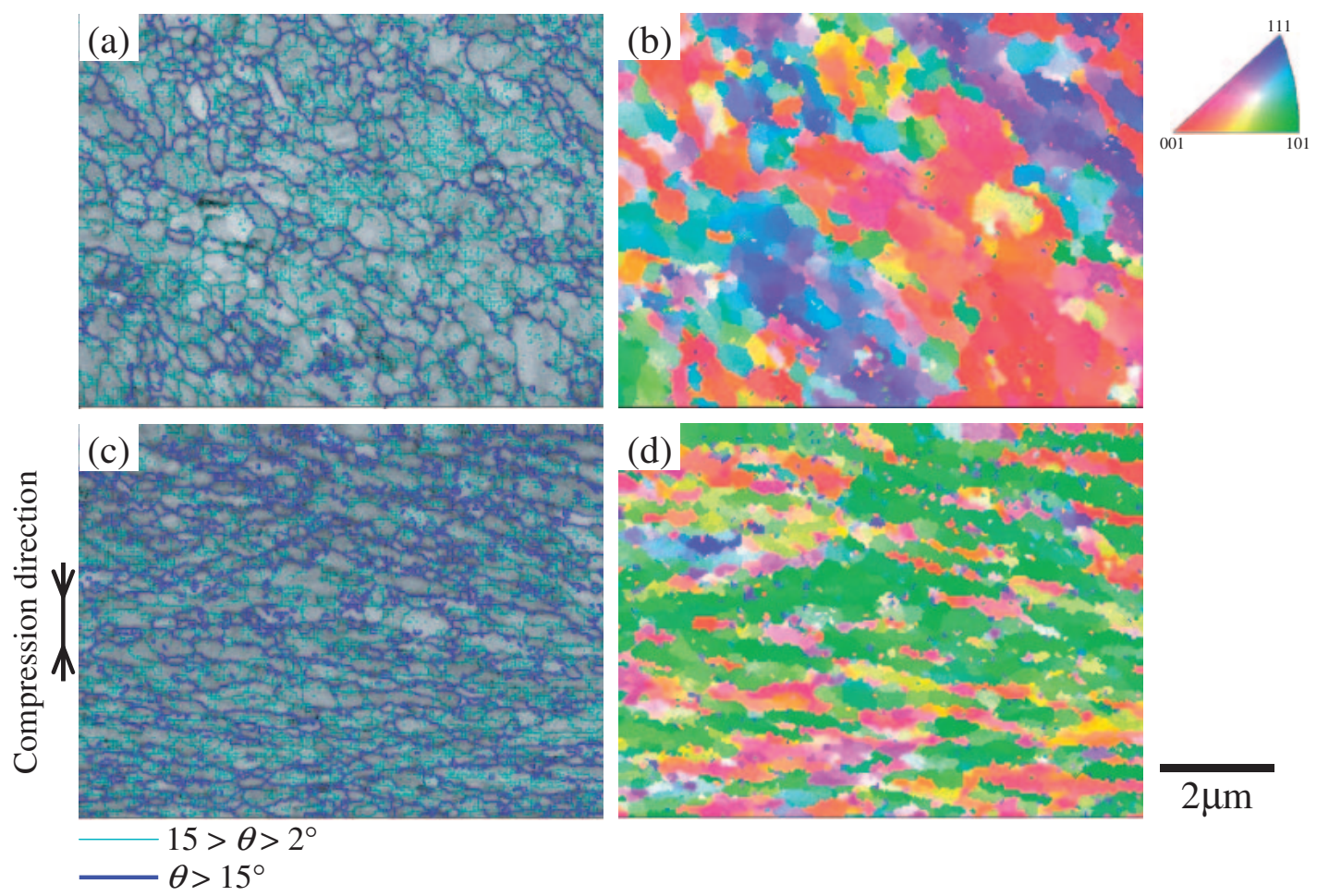

Fig. 7 EBSD maps obtained from (a), (b) the torsion and (c), (d) the longitudinal plane regions of $r=1.5 \mathrm{~mm}\left(\varepsilon_{\text {eq }}=2.3\right)$ after HPTstraining; $R=5 \mathrm{rpm}, N=1 / 4$, RT. (a), (c) Pattern quality maps overlapped with grain boundaries and (b), (d) orientation maps.
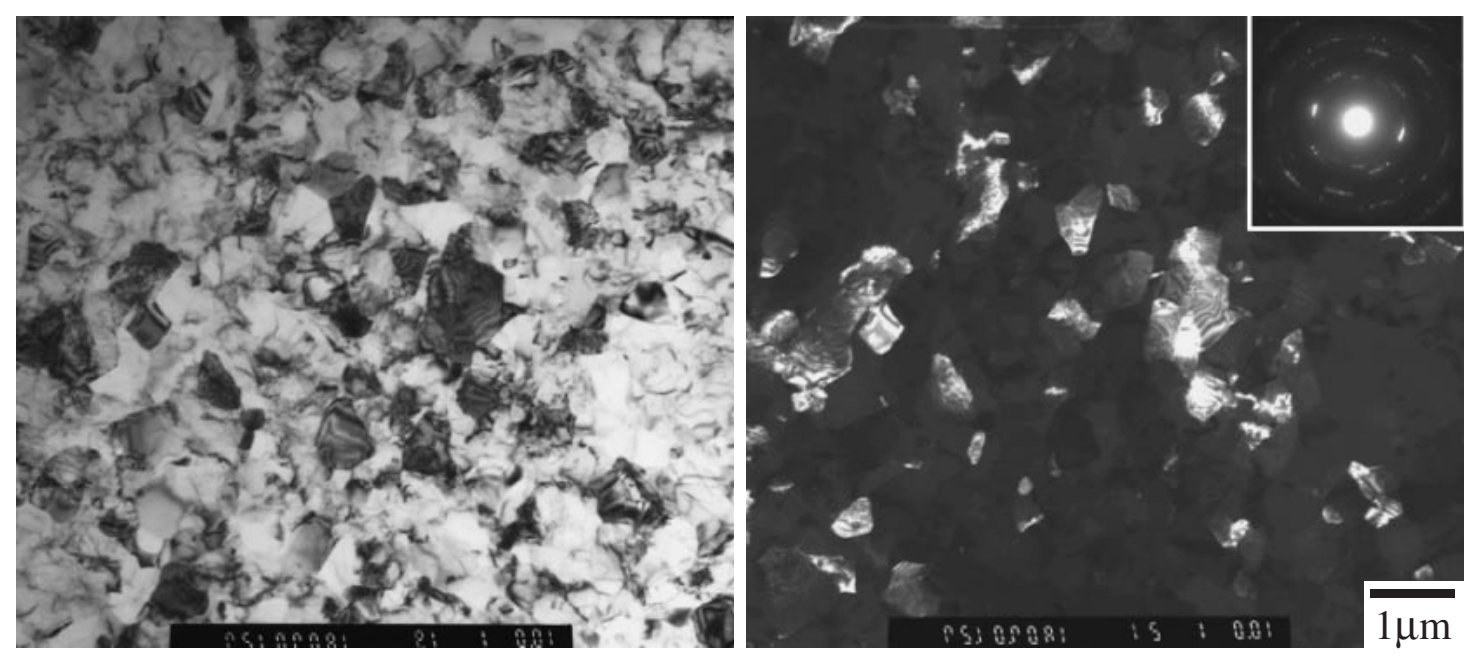

Fig. 8 Microstructure at the torsion plane region of $r=3.2 \mathrm{~mm}\left(\varepsilon_{e q}=4.8\right)$ after HPT-straining; $R=0.2 \mathrm{rpm}, N=1 / 4$, RT. The SAED pattern was taken form the area of $\phi 9.2 \mu \mathrm{m}$ in diameter in the $\mathrm{BF}$ image.

of $r=1.5 \mathrm{~mm}\left(\varepsilon_{e q}=2.3\right)$ after HPT-straining for $N=1 / 4$. In the torsion plane view, the deformed grains in micrometerscale with some subgrains are seen. These (sub)grains were elongated to the shear direction. This microstructure is consistent with that observed by TEM, as shown in Fig. 8. The BF image is analogous to those after $N=10$ at 0.2 or 5 rpm (Fig. 6). However, the DF image and the SAED pattern exhibit that the subgrains are of relatively low misorientation. While, the EBSD maps obtained from the longitudinal plane show band-like feature (Fig. 7(c), (d)). The (sub)grains were elongated along the direction perpendicular to torsion axis. As shown in Fig. 9, the grains became equiaxed with increase in strain. Figure 9 is SE micrographs taken by SIM. Contrast in the SE images taken by SIM is influenced by ion channeling effect, where the amount of SE which escapes from sample surface is a function of ion beam penetration depth into crystal lattice. The penetration depth depends on the crystal lattice orientation. Therefore, same contrast areas indicate grains with same orientation. The microstructures at the torsion plane regions of $r=1.5 \mathrm{~mm}\left(\varepsilon_{e q}=91\right)$ and $4.5 \mathrm{~mm}\left(\varepsilon_{e q}=270\right)$ after $N=10$ are similar to that at $r=3.2 \mathrm{~mm} \quad\left(\varepsilon_{e q}=190\right)$ observed by TEM (Fig. 6(b)). While, the slightly elongated grains can be seen at the longitudinal plane region of $r=1.5 \mathrm{~mm}$. Those grains changed to more equiaxed grains with increase in strain (the distance from the disk center, $r$ ). 

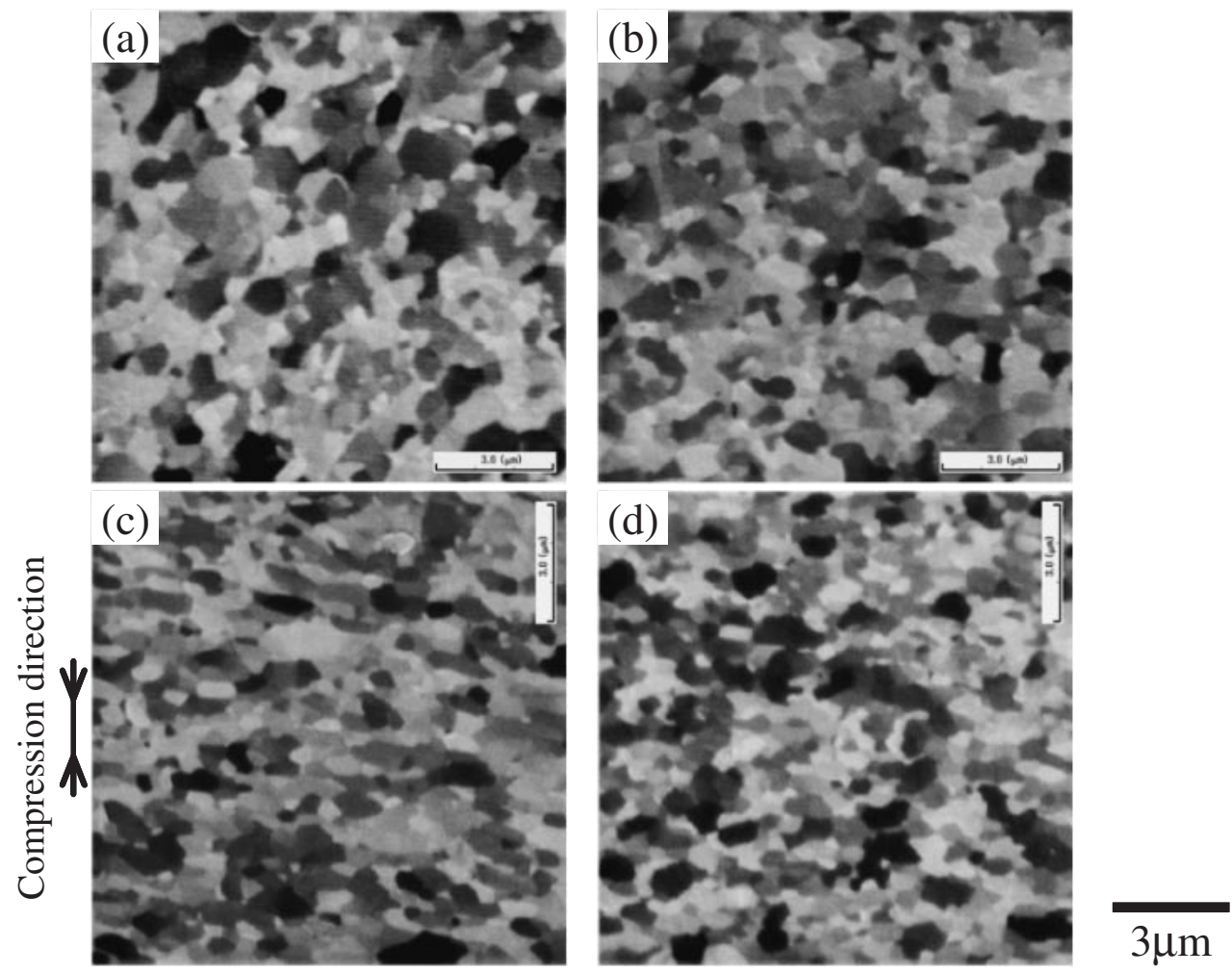

Fig. 9 SE micrographs by SIM taken from (a), (b) the torsion and (c), (d) the longitudinal planes after HPT-straining; $R=0.2$ rpm, $N=10$, RT. (a), (c) $r=1.5 \mathrm{~mm}\left(\varepsilon_{e q}=91\right)$ and (b), (d) $r=4.5 \mathrm{~mm}\left(\varepsilon_{e q}=270\right)$.

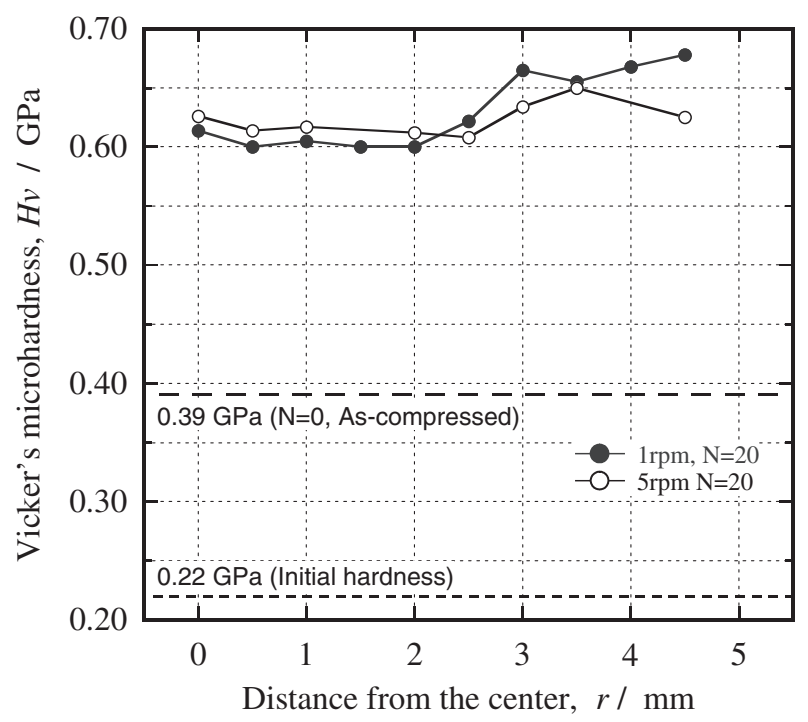

Fig. 10 Radial distributions of $H v$ in the disks processed by HPT at $R=1$ or $5 \mathrm{rpm}$ for $N=20$ in $\mathrm{LN}_{2}$.

\subsection{HPT-straining in $\mathbf{L N}_{2}$}

Figure 10 shows the $\mathrm{Hv}$ distributions of the disks after HPT-straining at $R=1$ or $5 \mathrm{rpm}$ for $N=20$ in $\mathrm{LN}_{2}$. The $H v$ distributions of the both disks are not so different. The $H v$ at the outer regions are higher than those at the center regions. This is because the degree of cooling by $\mathrm{LN}_{2}$ at the outer region was larger than the increment of temperature by deformation. The microstructure in the torsion plane of the disk after HPT-straining at $5 \mathrm{rpm}$ in $\mathrm{LN}_{2}$ consists of equiaxed grains (Fig. 11), and is similar to those observed in the HPTprocessed disks at 0.2 or $5 \mathrm{rpm}$ for $N=10$ at RT (Fig. 6).

\section{Discussions}

\subsection{Influence of HPT-straining conditions on obtained microstructure in CP-Al}

The obtained microstructures were hardly changed in the CP-Al after HPT-straining which was carried out under various conditions: $N=\sim 20\left(\varepsilon_{e q}=\sim 600\right), R=0.2,1,5$ $\mathrm{rpm}$, the ambient temperature of RT or $\mathrm{LN}_{2}$. Figure 12 shows the specimen temperature changes during HPT-straining. The attained specimen temperatures, $T_{a}$, after $N=10$ at 0.2 or $5 \mathrm{rpm}$ at RT were $20^{\circ} \mathrm{C}\left(T_{a} / T_{m}=0.31\right.$, where $T_{m}$ is melting 

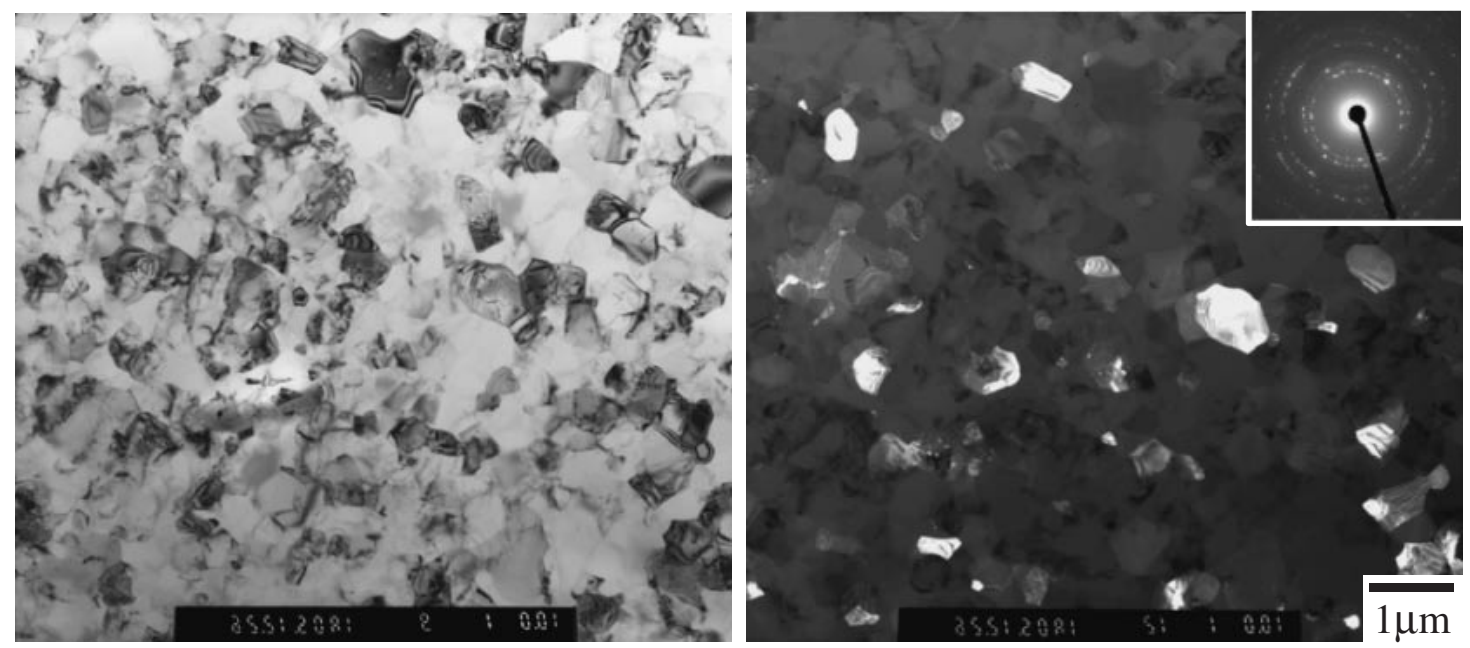

Fig. 11 Microstructure at the torsion plane region of $r=3.2 \mathrm{~mm}\left(\varepsilon_{e q}=390\right)$ after HPT-straining in $\mathrm{LN}_{2} ; R=5 \mathrm{rpm}, N=20$. The SAED pattern was taken form the area of $\phi 9.2 \mu \mathrm{m}$ in diameter in the $\mathrm{BF}$ image.

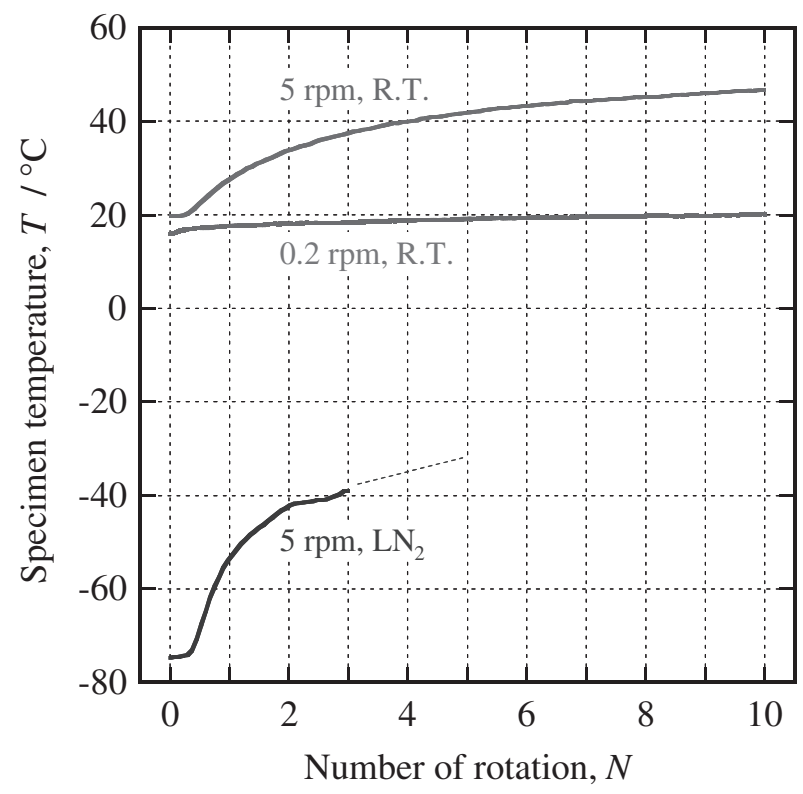

Fig. 12 Specimen temperature changes during HPT-straining.

point $)$ and $47^{\circ} \mathrm{C}\left(T_{a} / T_{m}=0.34\right)$ respectively. Zhilyaev et al. estimated the specimen temperature increment of $\sim 120$ $140^{\circ} \mathrm{C}$ from microstructure in Al-Si alloy after HPT-straining $\left.(N=5, R=1 \mathrm{rpm}, \mathrm{RT}, P=6 \mathrm{GPa}) .{ }^{16}\right)$ Their estimated value was higher than our measured ones because of the differences of materials and measurement position. The real specimen temperature at $5 \mathrm{rpm}$ in $\mathrm{LN}_{2}$ is probably lower than the apparent one (Fig. 12), because the measurement region was close to the poured $\mathrm{LN}_{2}$ surface. Thus, the difference of the maximal and minimal $T_{a}$ in this study can be assume about $100^{\circ} \mathrm{C}\left(T_{a} / T_{m}=0.24 \sim 0.34\right)$. It should be noted that equiaxed grains like the recrystallized structure obtained by heating were formed although the specimen temperature during HPT-straining was kept low enough in comparison with the $T_{m}$ of aluminum. It has been reported that the nonequilibrium structure with high density of lattice defects formed by HPT-straining. ${ }^{9,17)}$ In such structure, recovery, recrystallization and/or grain growth occur even with slight rising of specimen temperature. In addition, in the disks after HPT-straining at the lower temperature than RT, those microstructure changes occur by the subsequent rising of specimen temperature to RT $\left(T_{R T} / T_{m}=0.31\right.$, where $T_{R T}$ is RT). Therefore, despite the low $T_{a} / T_{m}$, the every microstructures obtained in this study were quite similar.

While, in our previous study, ${ }^{18)}$ the different microstructures of the commercial purity titanium (CP-Ti) after HPTstraining at $R=0.2$ or $5 \mathrm{rpm}$ for $N=10$ were observed: the equiaxed submicron-grain structure with high density of dislocation (Fig. 13(a)) and the elongated subgrain structure (Fig. 13(b)). The $T_{a}$ of the CP-Ti disks at 0.2 and $5 \mathrm{rpm}$ at RT were $30^{\circ} \mathrm{C}\left(T_{a} / T_{m}=0.16\right)$ and $180^{\circ} \mathrm{C} \quad\left(T_{a} / T_{m}=0.23\right)$ respectively. These indicate that the equiaxed submicronand nano- grain structure can form by keeping $T_{a} / T_{m}$ low enough since grain subdivision is facilitated with the accumulation of dislocations (the suppression of recovery).

In fact, nanocrystalline aluminum was prepared by mechanical attrition in $\mathrm{LN}_{2}{ }^{19)}$ which is known as cryomilling and one of SPD techniques. However, the high stability of its nanocrystalline structure was attributed to impurity pining of grain boundary. Therefore, although the $\mathrm{CP}-\mathrm{Al}$ could not be refined to submicron-scale by HPT-straining in this study, it seems that the submicron-grain structure can produce by HPT-straining at $T_{a} / T_{m}<0.24$ and preventing the occurrence of recovery, recrystallization and/or grain growth during the rising of specimen temperature to RT. To obtain the submicron- and nano- grained structure of the low Tm materials such aluminum, the presences of precipitations and/or solution elements are effective.

\subsection{Microstructure evolution of CP-Al during HPT- straining}

UFG structures produced by SPD consist of elongated (lamellar) or equiaxed (sub-)grains. The elongated structure is often observed after monotonic deformation, such as coldrolling, ${ }^{20)} \mathrm{ARB}^{21,22)}$ and HPT-straining. ${ }^{12,13)}$ On the other 

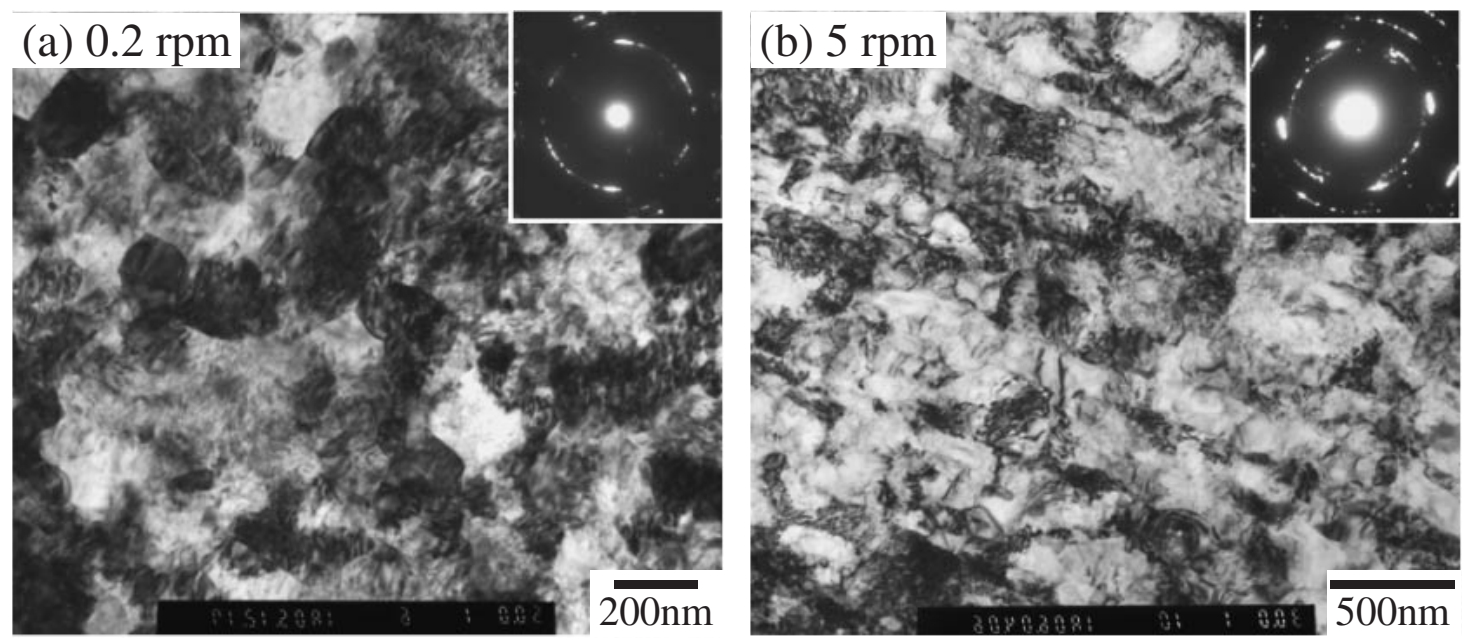

Fig. 13 Microstructures at the torsion plane region of $r=3.2 \mathrm{~mm}\left(\varepsilon_{e q}=190\right)$ in the commercial purity titanium after HPT-straining at (a) $0.2 \mathrm{rpm}\left(T_{a} / T_{m}=0.16\right)$ or (b) $5 \mathrm{rpm}\left(T_{a} / T_{m}=0.23\right)$ for $N=10$ at RT. The SAED patterns were taken form the areas of $\phi 2.1 \mu \mathrm{m}$ or $\phi$ $1.4 \mu \mathrm{m}$ in diameter in each of the BF images.

hand, the equiaxed structure is typically the result of multidirection deformation (strain path changes), e.g. ECAP. ${ }^{23}$ )

In the early stage $\left(\varepsilon_{e q}<\sim 10\right)$ of HPT-straining in this study, the lamellar (sub)structure formed (Fig. 7). The thickness of lamellar (sub)structure in the longitudinal plane and the grain diameter of subgrains in the torsion plane decreased to a certain size (about $500 \mathrm{~nm}$ ) with increase in $\varepsilon_{e q}$. As the same time, the misorientations of subgrains increased by the annihilations of dislocations (recovery process) during straining. In the middle stage $\left(\varepsilon_{e q}<\sim 100\right)$, the subgrains developed to the equiaxed grains with highangle boundaries via recovery process (which can be called either $i n-s i t u^{24)}$ or continuous recrystallization ${ }^{25)}$ ) in the torsion plane (Fig. 6, 9(a)) and the lamellar (sub)structure subdivided to the slight elongated grains (Fig. 9(c)). Such microstructures were observed in the ARBed specimens. ${ }^{3,21)}$ It is noteworthy that in the final stage $\left(\varepsilon_{e q}<\right.$ several hundreds) of HPT-straining the nearly equiaxed grains with about $500 \mathrm{~nm}$ in diameter formed via slight grain growth (Fig. 9(b), (d)). This equiaxed UFG structure is similar to that obtained by multi-direction deformation, e.g. ECAP with route $\mathrm{B}_{\mathrm{C}}{ }^{23)}$

\section{Conclusions}

In the present study, the influence of HPT-straining conditions on microstructure was investigated in $\mathrm{CP}-\mathrm{Al}$. The microstructures obtained after HPT-straining with large amounts of strain $\left(\varepsilon_{e q}>\sim 100\right)$ were hardly changed without relation to the specimen temperature of $T_{a} / T_{m}=0.24 \sim$ 0.34 under the various conditions: $R=0.2,1,5 \mathrm{rpm}$ and the ambient temperature of $\mathrm{RT}$ or $\mathrm{LN}_{2}$. The $\mathrm{Hv}$ of these microstructures were around $0.65 \mathrm{GPa}$. The microstructures developed from lamellar (sub)structure to equiaxed grain structure of about $500 \mathrm{~nm}$ in diameter with quite low dislocation density via grain subdivision, recovery, continuous recrystallization and grain growth during HPT-straining.

\section{Acknowledgments}

This study was financially supported in part by the Grantin-Aid for Scientific Research from the Ministry of Education, Culture, Sports, Science and Technology of Japan. The materials for the HPT disks (Al 1050) and the anvils (DRM2) used in this study were provided by Furukawa Electric Co., Ltd. and Daido Steel Co., Ltd. All these supports are gratefully appreciated by the authors.

\section{REFERENCES}

1) R. Z. Valiev, R. K. Islamgaliev and I. V. Alexandrov: Prog. Mater. Sci. 45 (2000) 103-189.

2) V. M. Segal, V. I. Reznikov, A. E. Drobyshevskiy and V. I. Kopylov: Russ. Metall. 1 (1981) 99-105.

3) Y. Saito, N. Tsuji, H. Utsunomiya, T. Sakai and R. G. Hong: Scr. Mater. 39 (1998) 1221-1227.

4) J. G. Sevillano: Proc. of 25th Riso Int. Symp. on Mater. Sci., ed. by C. Gundlach, K. Haldrup, N. Hansen, X. Huang, D. J. Jensen, T. Leffers, Z. J. Li, S. F. Nielsen, W. Pantleon, J. A. Wert and G. Winther, (Riso Natl Lab., Roskilde, Denmark, 2004) pp. 1-11.

5) Y. Todaka, M. Umemoto, Y. Watanabe, A. Yamazaki, C. Wang and K. Tsuchiya: ISIJ Int. 47 (2007) 157-162.

6) Y. Todaka, M. Umemoto, J. Yin, Z. Liu and K. Tsuchiya: Mater. Sci. Eng. A 462 (2007) 264-268.

7) P. W. Bridgman: Studies in Large Plastic Flow and Fracture, (McGraw-Hill, New York, 1952).

8) G. Sakai, Z. Horita and T. G. Langdon: Mater. Sci. Eng. A 393 (2005) 344-351.

9) R. Z. Valiev, Y. V. Ivanisenko, E. F. Rauch and B. Baudelet: Acta mater. 44 (1996) 4705

10) A. P. Zhilyaev, G. V. Nurislamova, B. K. Kim, M. D. Baro, J. A. Szpunar and T. G. Langdon: Acta Mater. 51 (2003) 753-765.

11) A. P. Zhilyaev, S. Lee, G. V. Nurislamova, R. Z. Valiev and T. G. Langdon: Scr. Mater. 44 (2001) 2753-2758.

12) T. Hebesberger, H. P. Stuwe, A. Vorhauer, F. Wetscher and R. Pippan: Acta Mater. 53 (2005) 393-402.

13) X. Huang, A. Vorhauer, G. Winther, N. Hansen, R. Pippan and M. Zehetbauer: Ultrafine Grained Materials III, ed. by Y. T. Zhu, T. G. Langdon, R. Z. Valiev, S. L. Semiatin, D. H. Shin and T. C. Lowe, (TMS, 2004) pp. 235-240.

14) C. Xu, Z. Horita and T. G. Langdon: Acta Mater. 55 (2007) 203212. 
15) A. P. Zhilyaev, K. Oh-ishi, T. G. Langdon and T. R. McNelley: Mater. Sci. Eng. A 410-411 (2005) 277-280.

16) A. P. Zhilyaev, J. M. Garcia-Infanta, F. Carreno, T. G. Langdon and O. A. Ruano: Scr. Mater. 57 (2007) 763-765.

17) Z. Horita, D. J. Smith, M. Furukawa, M. Nemoto, R. Z. Valiev and T. G. Langdon: J. Mater. Res. 11 (1996) 1880-1890.

18) Y. Todaka, M. Umemoto, A. Yamazaki, J. Sasaki and K. Tsuchiya: Proc. of the 11th World Conf. on Titanium, (The Japan Institute of Metals, Japan, 2007) in press.

19) F. Zhou, J. Lee, S. Dallek and E. J. Lavernia: J. Mater. Res. 16 (2001) 3451-3458.

20) Q. Liu, X. Huang, D. J. Lloyd and N. Hansen: Acta Mater. 50 (2002)
3789-3802.

21) X. Huang, N. Tsuji, N. Hansen and Y. Minamino: Mater. Sci. Eng. A 340 (2003) 265-271.

22) N. Tsuji, R. Ueji and Y. Minamino: Scr. Mater. 47 (2002) 69-76.

23) Y. Iwahashi, Z. Horita, M. Nemoto and T. G. Langdon: Acta Mater. 46 (1998) 3317-3331.

24) N. Tsuji, R. Ueji, Y. Ito and Y. Saito: Proc. of 21st Riso Int. Symp. on Mater. Sci., ed. by N. Hansen, X. Huang, D. J. Jensen, E. M. Lauridsen, T. Leffers, T. J. Sabin and J. A. Wert, (Riso Natl Lab., Roskilde, Denmark, 2000) pp. 607-616.

25) A. Belyakov, T. Sakai and H. Miura: Mater. Trans., JIM 41 (2000) 476484 . 